\title{
Evidence for a Role of Oxytocin Receptors in the Long-Term Establishment of Dominance Hierarchies
}

\author{
Marjan Timmer', M Isabel Cordero', Yannick Sevelinges' and Carmen Sandi*,' \\ 'Laboratory of Behavioral Genetics, Brain Mind Institute, Ecole Polytechnique Fédérale de Lausanne (EFPL), Lausanne, Switzerland
}

\begin{abstract}
Exposure to stress can affect the establishment of dominance hierarchies. In our model, a social hierarchy established by two male rats during a first encounter is not maintained I week later. If one of the two rats is stressed, the stressed rat becomes subordinate and the hierarchy that is formed is maintained. In this study, we investigated the changes in the expression of oxytocin (Otr) and vasopressin (VIaR) receptor genes in the medial amygdala (MeA) and the lateral septum (LS) in the hours following hierarchy establishment under both stressed and basal conditions. We found that the potentiation of a social hierarchy induced by stress is accompanied by social status- and region-specific changes in the expression of Otr mRNA in the MeA $3 \mathrm{~h}$ after the social encounter. At this time point, no evidence was found for the regulation of VIaR mRNA in any of the brain regions examined. Results from pharmacological experiments involving the microinfusion of a specific OTR antagonist immediately after the acquisition of a subordinate status under basal, non-stress conditions suggested a role for this receptor in the MeA on the long-term establishment of the subordinate status. Altogether, these findings highlight a role for the oxytocinergic system in the mechanisms through which stress facilitates the long-term establishment of a social hierarchy.

Neuropsychopharmacology (20II) 36, 2349-2356; doi: 10.1038/npp.20II.I25; published online I3 July 201 I
\end{abstract}

Keywords: oxytocin; vasopressin; dominance hierarchy; rat; medial amygdala; lateral septum

\section{INTRODUCTION}

In most animals that live in groups, males establish dominance hierarchies in which the dominant animal has priority access to limited resources, such as water, food, space, and females. One of the main functions of establishing dominance hierarchies is to eliminate fighting within a group, thus minimizing energy costs (Van Kreveld, 1970). In laboratory rats that are kept in a colony, a stable hierarchy usually develops within a few days (Blanchard et al, 1988).

Social recognition and social memory are critical for the establishment and maintenance of social relationships, including social attachment, sexual behavior, parental care, and dominance hierarchies (Bielsky and Young, 2004). Social memory for offspring and mates usually lasts for days, months or even years (Ferguson et al, 2002). However, recognition of an unfamiliar individual tends to be short lasting, in the range of minutes to hours. Because of the importance of social recognition, the hypothesis has been put forward that specific pathways in the brain have developed for this purpose. Among the brain areas

*Correspondence: Professor C Sandi, Brain Mind Institute, Ecole Polytechnique Fédérale de Lausanne (EFPL), Station 19, Lausanne I015, Switzerland, Tel: +4I 2169317 62, Fax: +4I 2169396 36, E-mail: carmen.sandi@epfl.ch

Received 23 February 20 I I; revised 7 June 20 I I; accepted 9 June 201 I implicated in these pathways are the medial amygdala (MeA) and lateral septum (LS) (Ferguson et al, 2002; Bielsky and Young, 2004).

Oxytocin (OT) and arginine vasopressin (AVP) are two neuropeptides that have an important role in the regulation of social behavior (for a review, see Veenema and Neumann, 2008). These neuropeptides and their receptors, oxytocin receptor (OTR) and vasopressin receptor $1 \mathrm{a}(\mathrm{V} 1 \mathrm{aR})$, are expressed in brain areas, such as MeA and LS, which are involved in social behavior (Ostrowski et al, 1994; Landgraf et al, 1998; Ostrowski, 1998; Newman, 1999; Engelmann et al, 2000; Gimpl and Fahrenholz, 2001; Goodson, 2005). OT or V1aR knockout mice are not able to form social memories (Ferguson et al, 2000, 2001; Bielsky et al, 2004; Crawley et al, 2007). The administration of OT to OT knockout mice before a social encounter or the re-expression of $\mathrm{VlaR}$ in $\mathrm{VlaR}$ knockout mice restores the ability to form social memories (Ferguson et al, 2000; Bielsky et al, 2005). In rats, administration of AVP or low, but not high, doses of OT facilitates social recognition (Popik and Van Ree, 1991; Popik and Vetulani, 1991; Popik et al, 1992; Benelli et al, 1995), whereas administration of OTR or V1aR antagonists blocks social recognition (Dantzer et al, 1987, 1988; Le Moal et al, 1987; Popik and Van Ree, 1991; Popik and Vetulani, 1991; Popik et al, 1992, 1996; Benelli et al, 1995; Engelmann et al, 1996, 1998; van Wimersma Greidanus and Maigret, 1996; Everts and 
Table I Overview of the used Gene Expression Assays (Applied Biosystems)

\begin{tabular}{ll}
\hline Gene & Gene expression assay \\
\hline Oxytocin receptor (Otr) & Rn00563503_m l \\
Arginine vasopressin receptor Ia (VIar) & Rn005839I0_ml \\
Ribosomal protein SI8 (Rps / 8) & Rn0I4289I5_gl \\
Ribosomal protein S29 (Rps29) & Rn00820645_gl \\
Eukaryotic elongation factor lal (Eeflal) & Rn0l63985I_gl \\
\hline
\end{tabular}

Koolhaas, 1997, 1999; Landgraf et al, 2003; Choleris et al, 2007). In addition to its role in social recognition, AVP has also been implicated in aggressive behavior (Ferris et al, 1984; Irvin et al, 1990; Winslow and Insel, 1993; Delville et al, 1996).

In rats, exposure to different types of emotional and physical stressors has been reported to lead to OT and AVP release in different brain areas (Engelmann et al, 1999; Ebner et al, 2000; Wotjak et al, 1996, 1998; Neumann, 2007). Glucocorticoids were shown to modulate OTR- and V1aRbinding sites in different brain areas, including the amygdala and LS (Patchev et al, 1993; Watters et al, 1996). It has been suggested that interactions between OT, AVP, and glucocorticoids could provide a mechanism for dynamic changes in social behavior (Gimpl and Fahrenholz, 2001).

We have developed a rat model, in which stress experienced by one individual just before a first social encounter with another male equivalent in body weight and trait anxiety leads to submission in the stressed animal and the establishment of a dominance hierarchy that remains stable for at least 1 week (Cordero and Sandi, 2007). This finding contrasts with the short-lasting social hierarchy that develops in non-stressed rats, which is no longer present 1 week after a first encounter (Cordero and Sandi, 2007). Moreover, in unstressed dyads, a long-term hierarchy was facilitated when the subordinate, but not the dominant, rat received corticosterone post-encounter (Timmer and Sandi, 2010), suggesting that memory facilitation by stress is primarily retained by the subordinate rat. Here, we hypothesized a role for OTR and V1aR in the MeA and LS in the stress-induced facilitation of the established long-term dominance hierarchy. We investigated the changes in gene expression for the Otr and VlaR in each brain region following hierarchy establishment under stressed and basal conditions. We then studied the impact of pharmacologically antagonizing the receptors according to the gene expression data, and evaluating the effects on the establishment of a long-term hierarchy.

\section{MATERIALS AND METHODS}

\section{Animals}

Male naïve Wistar rats (Charles River Laboratories, Lyon, France) weighing $250-275 \mathrm{~g}$ on arrival were individually housed with ad libitum access to food and water. The rats were left undisturbed for 1 week before the start of the experiments. Animals were kept on a 12-h light/dark cycle with lights on at 0700 hours at a constant temperature of
$22 \pm 2{ }^{\circ} \mathrm{C}$. Experiments were carried out in accordance with the European Communities Council Directive of 24 November 1986 (86/609/EEC) and approved through a license issued by the Cantonal Veterinary Authorities (Vaud, Switzerland).

All experiments took place between 0800 and 1400 hours, except for the water competition test, which took place between 1400 and 1900 hours after a water deprivation period of $6 \mathrm{~h}$ (from 0800 to 1400 hours). All rats were handled for $2 \mathrm{~min}$ per day for 3 days before exposure to the elevated plus maze (see below).

\section{Elevated Plus Maze (EPM)}

Before the start of the social hierarchy experiment, the elevated plus maze (EPM) test was performed to measure anxiety-related behavior (Herrero et al, 2006). The EPM consists of two opposing open arms $(45 \times 10 \mathrm{~cm})$ and two opposing closed arms $(45 \times 10 \mathrm{~cm}$ with walls $50 \mathrm{~cm}$ high $)$ that extend from a central platform $(10 \times 10 \mathrm{~cm})$ elevated $65 \mathrm{~cm}$ above the floor. The rats were individually placed on the central platform facing the same closed arm and were allowed to explore the EPM freely for $5 \mathrm{~min}$. The behavior of each rat was video recorded and analyzed using a computerized tracking system (Ethovision 3.1.16, Noldus IT, The Netherlands). Time spent in the open and closed arms was measured.

\section{Dyads and Experimental Groups}

Rats were distributed to dyads consisting of two rats that were matched for their body weight and anxiety level. The anxiety level was defined by the time spent in the open arms of the EPM. Thus, the rats in each dyad were considered equal in their probability to become dominant or subordinate during a first encounter. The fur of both rats in a dyad was marked on different body parts to help identify the animals. Rats were habituated to marking during the 3day habituation period that took place before the first social encounter. Dyads were divided randomly over the different groups (non-stressed pairs or stressed pairs). Each group consisted of 7-14 dyads.

\section{Stress Delivery}

In non-stressed pairs (Pns), none of the rats was stressed before the social encounter. In stressed pairs (Ps), one rat of the pair was stressed just before the first social encounter. Stress consisted of exposure to three-foot shocks of $1 \mathrm{~mA}$ with an intershock interval of $1 \mathrm{~min}$. At $30 \mathrm{sec}$ after the last shock, the rat was taken out and immediately submitted to the first social encounter with an unfamiliar rat in an adjacent room. See Supplementary Materials and Methods for a detailed description of stress delivery.

\section{Food and Water Competition Test}

The animals were given eight Chocopop flakes (Kellogg's, Switzerland) in their homecages daily for 2 days before the start of the habituation to the experimental setup to habituate them to the rewarding food used in the food competition test (FCT). The rats were habituated to the 
experimental setup for 3 days, during which they were first placed individually in a clean housing cage for $20 \mathrm{~min}$ and then in a food competition box for $10 \mathrm{~min}$. The food competition box is a $60 \times 40 \mathrm{~cm}$ plastic box with a $32-\mathrm{cm}$ high walls and a feeder containing eight Chocopops on one of the short sides. On day 1 of the experiment, the day after the last habituation day, the rats were submitted to a first encounter with an unfamiliar rat (a social interaction test) in a neutral housing cage without food and water for $20 \mathrm{~min}$, followed by a FCT in which the rats had to compete for Chocopops for 10 min (see Supplementary Materials). After the tests, each rat was returned to its homecage. The group without an encounter on day 1 was exposed to an extra day of habituation.

The memory for the formed hierarchy was tested in a water competition test (WCT) that was performed on day 8 following a water deprivation period of $6 \mathrm{~h}$. Rats were exposed to the same opponent as on day 1. The WCT was performed in a neutral homecage. After 2 min of habituation, a single bottle of water was presented and the behavior during the following 10 min was recorded. Figure 1a shows a scheme with the time line of the experiments.
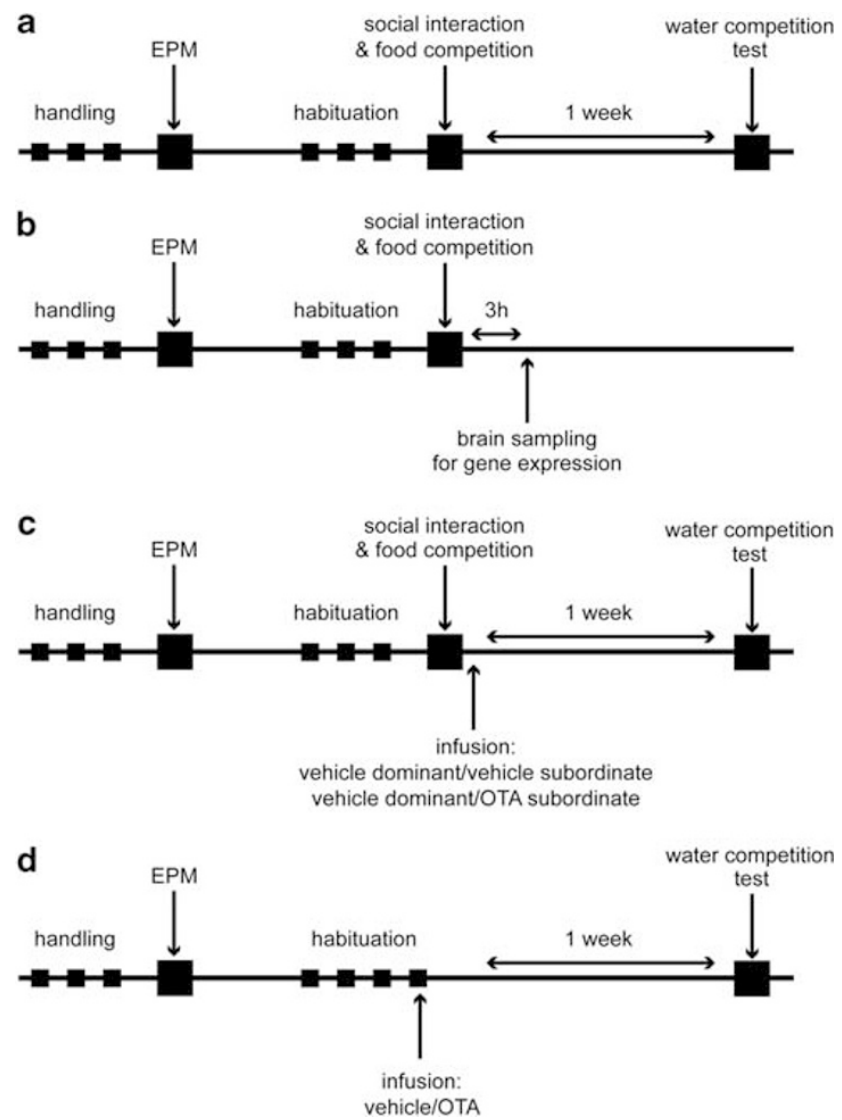

Figure I Scheme showing the time line of the experiments (a) The time line for the standard experiment. (b) The time line for the experiment including brain sampling $3 \mathrm{~h}$ after the first encounter for gene expression analyses. (c) The time line for the experiment, in which rats in each pair received infusions into the $\mathrm{MeA}$ immediately after the first encounter of either vehicle in both cases or vehicle to the dominant rat and OTA to the subordinate rat. (d) The time line for the control experiment, in which rats in each pair were, respectively, infused with either vehicle or OTA into the MeA I week before their social encounter.
Behavior was video recorded and scored blindly using The Observer software (v.5.0.25, Noldus IT, The Netherlands). The duration and frequency of offensive and defensive behaviors were scored. Offensive behaviors were attacks, keeping down, offensive upright, and lateral threat. Defensive behavior consisted of freezing, defensive upright, and submissive posture (as described in Timmer and Sandi, 2010). The rat that showed the most offensive behaviors during the interaction was considered the dominant rat, and the rat showing the least offensive behaviors and the most defensive behaviors was considered the subordinate rat.

Two control groups were added for the gene expression experiment. The first control group was submitted to habituation, but not to a social encounter. The stressed control group was submitted to habituation and to footshock stress (as described above) but not to a social encounter.

\section{Brain Sampling and Gene Expression}

For the gene expression experiment rats were killed $3 \mathrm{~h}$ after the end of the FCT. The animals were decapitated, and the brains were quickly removed, frozen in isopentane at a temperature between -50 and $-40{ }^{\circ} \mathrm{C}$, and stored at $-80{ }^{\circ} \mathrm{C}$ until further processing. Figure $1 \mathrm{~b}$ shows a scheme with the time line of the experiments. See Supplementary Materials and Methods for details on the processing of the samples for real-time PCR (Table 1).

To check the position of the cannulae in the OTA antagonist experiment, rats were decapitated, and the brains were removed, frozen in isopentane, and stored at $-80{ }^{\circ} \mathrm{C}$ until further processing. Coronal sections (40- $\mu \mathrm{m}$ thick) were stained with thionin to detect the cannulae position. Animals in which the cannula was not in the right location were eliminated from the study.

\section{Drugs and Infusion Procedure}

The selective OT antagonist (OTA) desGly- $\mathrm{NH}_{2}-\mathrm{d}\left(\mathrm{CH}_{2}\right)_{5}[\mathrm{D}-$ $\mathrm{Tyr}^{2}$, Thr ${ }^{4}$ ]OVT was used for infusions into the MeA (generous gift of Dr M Manning, Toledo, OH, USA). For details on the procedures followed for surgery and cannulation, see Supplementary Materials and Methods. The OTA antagonist was dissolved in saline. For MeA infusions, $11-\mathrm{mm}$ internal injectors (extending $1 \mathrm{~mm}$ from the end of the guide cannula, 30 gauge, Plastics One) were used to administer the drug. The injectors were connected to $10 \mu \mathrm{l}$ microsyringes (SGE Analytical Science, Australia) on an automated infusion pump (Harvard Apparatus, Holliston, MA, USA) through polyethylene tubing. Drug dose was selected according to previous evidence in the literature. Thus, $1 \mu \mathrm{g}$ of OTA (Neumann et al, 2000) in $1 \mu \mathrm{l}$ of saline was infused into the MeA of each hemisphere at a rate of $0.5 \mu \mathrm{l} / \mathrm{min}$. After infusion, the injector was left in place for $1 \mathrm{~min}$ to allow diffusion of the drug. Saline was used as a vehicle. The OTA was infused into the subordinate rat immediately after the encounter or after the last habituation session in the group that was not exposed to a social encounter on day 1 , which corresponds with the time when a change in OTR mRNA levels was found. The other rat of each pair and both rats from control pairs were infused with vehicle. In addition, a control experiment was 
performed in which animals were injected with either vehicle or OTA without concomitant exposure to social encounter and their social rank was tested 1 week after injection. Figures $1 \mathrm{c}$ and $\mathrm{d}$ show the experimental time line of the drug experiments.

\section{Statistics}

All results are expressed as the mean \pm SEM. For the behavioral experiments, the percentage of offensive behaviors for each rat within each dyad was calculated. A paired two-tailed Student's $t$-test was used to compare the percentage of offensive behaviors within a dyad of rats competing together. For statistical analyses of mRNA expression levels, data for experimental groups are expressed as fold change with regards to the non-stressed control group. ANOVA was performed to compare the mRNA expression levels across the different experimental groups (ie, dominant and subordinate rats from each dyad) and post how LSD tests performed when appropriate. Only significant results are indicated in the text. The computer software SPSS for Windows (v.13.0) was used for statistical analysis. $P \leqslant 0.05$ was considered significant.

\section{RESULTS}

Exposure to Acute Stress Induces a Long-Term Memory for the Established Hierarchy

First, we confirmed our previous observation that exposing one rat of a dyad to acute stress before a first encounter induces a long-term memory for the establishment of a hierarchy that is not observed in non-stressed dyads (Cordero and Sandi, 2007). As expected, we found that under non-stress conditions (Pns, consisting of two nonstressed rats, Rns), rats form a hierarchy when exposed to a first social encounter on day $1(t=7.84, \mathrm{df}=6, p<0.001)$, but the hierarchy is not maintained on day 8 (Figure 2a). In the condition, in which one of the rats in each dyad is exposed to acute stress (Ps, consisting of one non-stressed rat Rns and one stressed rat Rs), the stressed rat becomes subordinate during the first encounter, and the hierarchy is still observed 1 week later $(t=5.08, \mathrm{df}=5, p<0.01$ for day $1, t=3.11, \mathrm{df}=5, p<0.05$ for day 8 , Figure $2 \mathrm{~b}$ ).

\section{OTR and V1ar mRNA Expression $3 \mathrm{~h}$ after a First Social Encounter}

Next, we evaluated the effects of stress and hierarchy formation on the expression levels of Otr and Vlar mRNA in the MeA and LS occurring in the $3 \mathrm{~h}$ after the first social encounter. At the behavioral level, we confirmed that both Pns and Ps dyads established a dominance hierarchy during the first social encounter $(t=2.80, \mathrm{df}=25, p<0.01$, Figure 3). Rats from each experimental group were killed $3 \mathrm{~h}$ after the end of the first encounter.

ANOVA indicated a difference in Otr mRNA expression in the MeA across the different experimental groups $\left(\mathrm{F}_{3,48}=2.87, p<0.05\right.$, Figure $\left.4 \mathrm{a}\right)$. Post hoc tests show that animals from the Ps subordinate group displayed significantly lower Otr mRNA expression in MeA than each of the other experimental groups ( $v s$ Ps dominant rats: $p<0.01$;

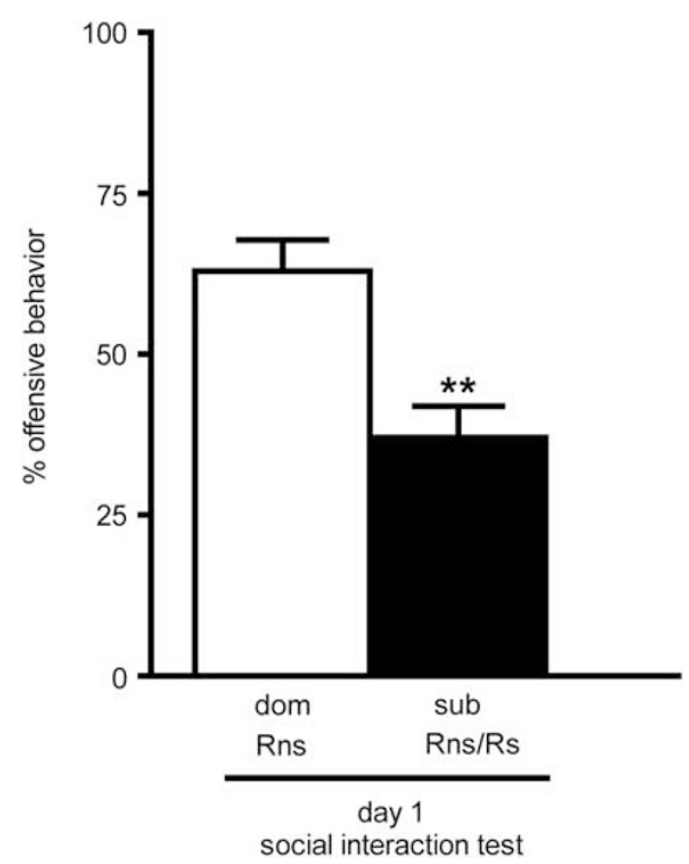

Figure 3 Percentage of total offensive behaviors (mean \pm SEM) between two opponents of non-stressed and stressed pairs in the social interaction test on day I $(n=20)$. dom, dominant; sub, subordinate; Rns, non-stressed rat; Rs, stressed rat. $* * * 0.01$ vs the other rat of the dyad.
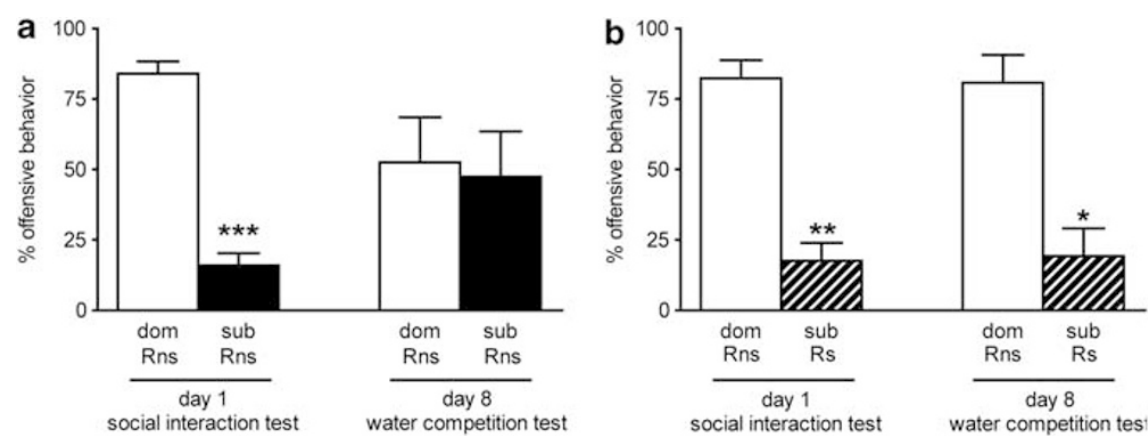

Figure 2 Percentage of total offensive behaviors (mean \pm SEM) between two opponents in the social interaction test on day I and the water competition test on day 8. (a) The hierarchy of rats of non-stressed pairs $(n=7)$. (b) The hierarchy of rats of the stressed pairs $(n=6)$. The status 'dom' (dominant) or 'sub' (subordinate) refers to the status that was obtained during the social interaction test on day I. Rns, non-stressed rat; Rs, stressed rat. * $p<0.05$, *** $p<0.0$ I, ***** $p<0.00$ I vs the other rat of the dyad. 


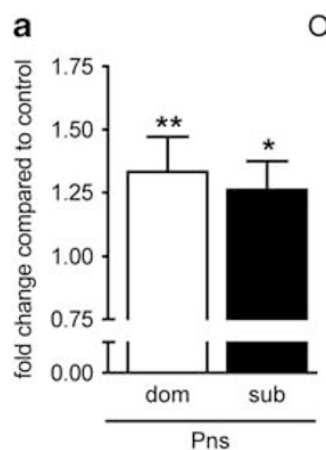

OTR

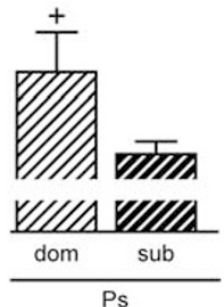

b

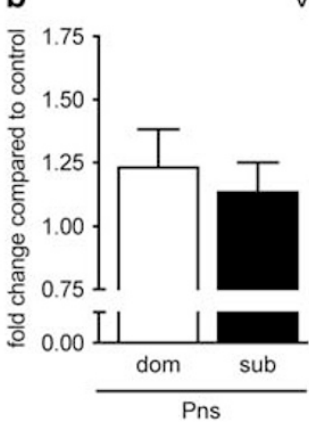

V1aR

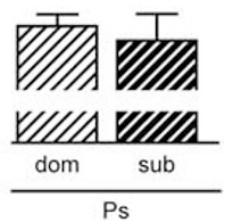

Figure 4 Expression of neuropeptide receptors in the MeA $3 \mathrm{~h}$ after the first social encounter (meant \pm SEM). (a) Expression of Otr mRNA. (b) Expression of VI ar mRNA. Dom, dominant; sub, subordinate; Pns, non-stressed pair; Ps, stressed pair. ${ }^{+} p<0.08,{ }^{*} p>0.05$, *** $p>0.0$ I vs Ps subordinate. Each group consists of $12-14$ animals.

vs Pns subordinate rats: $p<0.05$; vs Pns dominant rats: $p<0.08$; note that the latter only shows a trend towards significance). The stress control group did not differ from unstressed controls $(0.95 \pm 0.1$ for stressed controls, $1.00 \pm 0.1$ for unstressed controls, ns, Figure 4a). At this time point, no significant differences between groups were observed for V1ar mRNA levels in either the MeA (Figure 4b), not for Otr or V1ar mRNA expression levels in LS (data not shown).

\section{Infusion of a Selective OTA into the MeA}

Given that the Ps subordinate group showed significantly lower Otr mRNA levels in the MeA than the other experimental groups $3 \mathrm{~h}$ after the first encounter, we reasoned that if this molecular change is involved in the long-term maintenance of the hierarchy, antagonizing OTRs in subordinate males that had not been previously stressed would facilitate a long-term establishment of the hierarchy. Therefore, in this experiment, we micro-infused a selective OTR antagonist (OTA), desGly- $\mathrm{NH}_{2}-\mathrm{d}\left(\mathrm{CH}_{2}\right)_{5}$ [D-Tyr ${ }^{2}, \mathrm{Thr}^{4}$ ]OVT, $1 \mu \mathrm{g} / \mu \mathrm{l}$, into the MeA of non-stressed (Pns) subordinate rats immediately after the first encounter on day 1. The long-term establishment of the hierarchy was tested in a WCT 1 week after the first encounter. As a control, we verified that vehicle infusions given in the MeA immediately after hierarchy establishment on a first encounter $(t=10.07, \mathrm{df}=7, p<0.001)$ did not affect the outcome of the hierarchy normally observed in non-infused, unstressed animals when tested 1 week later. As shown in Figure 5a, no evidence for a memory of the hierarchy was observed at this later time point. As hypothesized, when OTA was infused into the subordinate rat immediately after the first encounter $(t=3.34, \mathrm{df}=9, p<0.01)$, the hierarchy is maintained 1 week later $(t=2.91, \mathrm{df}=9$, $p<0.05$, Figure $5 \mathrm{~b}$ ), suggesting a role for OTR in MeA in the long-term establishment of a hierarchy. In addition, to exclude a potential delayed effect of OTA infusion independent of its association with the formation of a social hierarchy, we infused OTA into the MeA in one rat per dyad, and we tested its effect on the establishment of a hierarchy 1 week later. As shown in Figure 5c, no effect was found in the establishment of a hierarchy during the WCT on day 8 when OTA was infused on day 1 in animals that did not receive an associated social encounter. Figure $5 \mathrm{~d}$ shows a representative example of the injection site in the MeA.

\section{DISCUSSION}

This study shows that the potentiation of a stress-induced social hierarchy in male rats is accompanied by social status- and region-specific changes in the expression of $\mathrm{Otr}$ mRNA levels in the MeA during the hours after the hierarchy establishment. As previously shown (Cordero and Sandi, 2007), the dominance hierarchy established between a pair of rats confronted for the first time under our experimental conditions is not maintained during a second competition test 1 week later. However, when one animal from each dyad was stressed, the stressed rat became subordinate during the first encounter; the same hierarchy was observed in a WCT 1 week later. Thus, $3 \mathrm{~h}$ following the first social encounter, the Ps subordinate group showed lower Otr mRNA expression levels in the MeA than animals that become subordinate without having been submitted to former stress and whose established hierarchy is not maintained 1 week afterwards. No evidence was found for changes in the expression of V1ar mRNA in the MeA, or for the levels of any of these two receptor types in the LS.

In a pharmacological experiment designed to antagonize OTR in the MeA following the establishment of a subordinate status under unstressed conditions, a long-term facilitation of the subordinate status and social hierarchy was found. Specifically, a long-term expression of the dominance hierarchy was promoted by microinfusing rats in the Pns subordinate group (from the Pns dyads that do not form an enduring hierarchy), with the OTR antagonist into the MeA immediately after the first social encounter. Notably, further pharmacological experiments excluded potential effects of the oxytocin antagonist that were not associated to the social processes under study. Thus, when the antagonist was administered in the MeA in animals that were not exposed to a first social confrontation, no effect was observed in the WCT performed 1 week afterwards. These results support the hypothesis that the effects of antagonizing OTR in the MeA after a first encounter are dependent on their combination with the social experience.

Substantial evidence indicates that the neuropeptides OT and AVP have an important role in the regulation of social behaviors (Ferguson et al, 2000, 2001; Bielsky and Young, 2004; Crawley et al, 2007). The effect of OT on social recognition in males has been suggested to follow an inverted U-shape response, with administration of low doses of OT facilitating and high doses inhibiting 


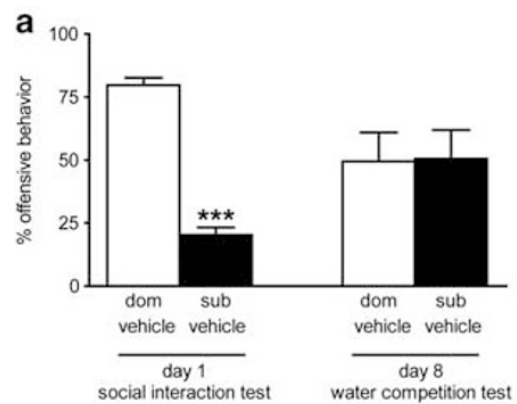

d

b
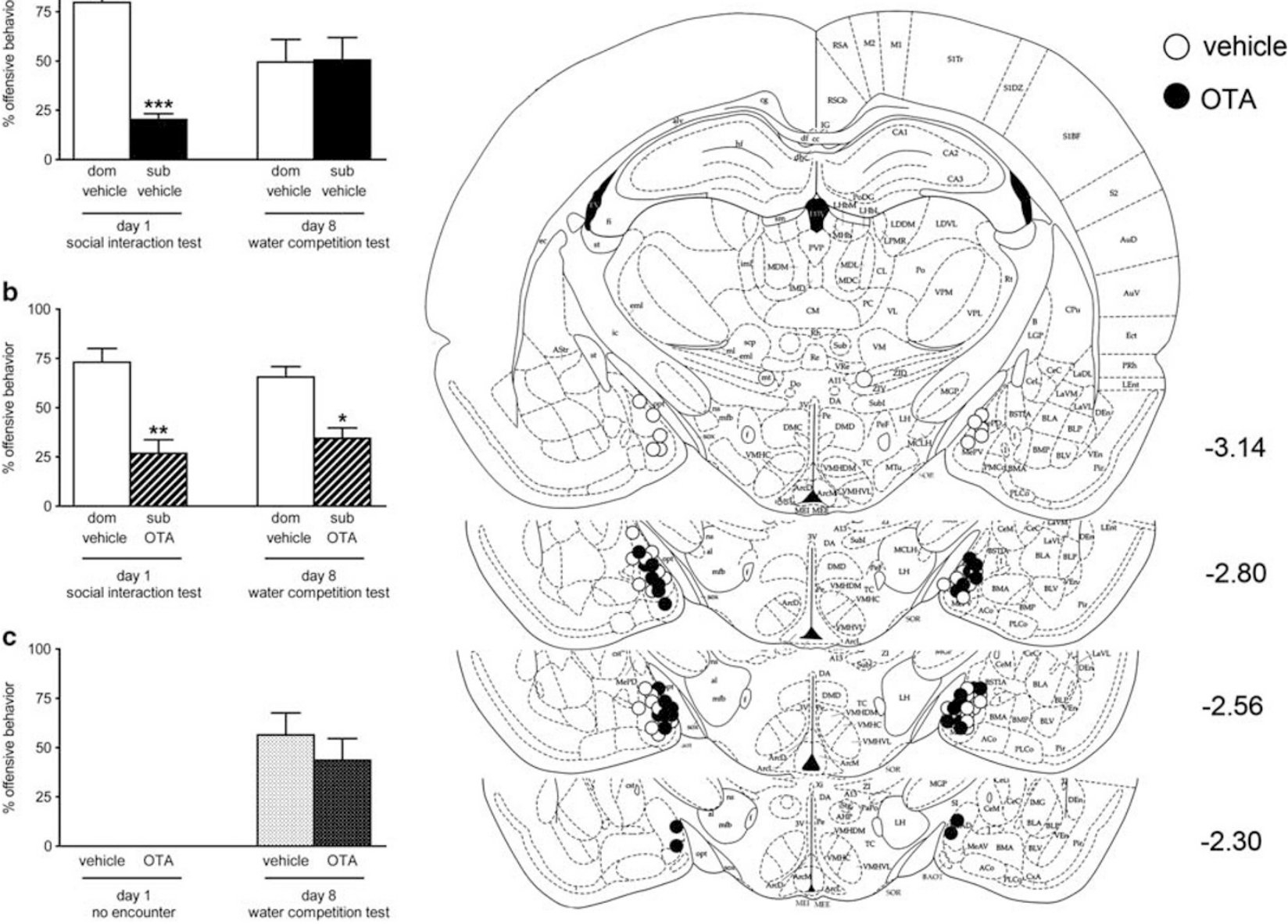

Figure 5 Percentage of total offensive behaviors (mean \pm SEM) between two opponents in the social interaction test on day I and the water competition test on day 8. (a) The hierarchy of rats that were infused with vehicle $(n=8)$. (b) Dyads in which the subordinate rat was infused with OTA immediately after the first encounter $(n=10)$. (c) Rats that were infused with either vehicle or OTA on day I without exposure to an encounter until day 8 ( $n=7$ ). (d) Schematic representation of the injection site into the MeA. The status 'dom' (dominant) or 'sub' (subordinate) refers to the status that was obtained during the social interaction test on day I. OTA, oxytocin antagonist. $* p<0.05$, $* * * 0.0$ I, $* * * *<0.00$ I vs the counterpart rat of each dyad.

recognition of a juvenile rat (Popik and Van Ree, 1991; Popik and Vetulani, 1991; Popik et al, 1992; Benelli et al, 1995). In females, infusions of either OTA (Engelmann et al, 1998) or OTR antisense DNA into the MeA (Choleris et al, 2007) interferes with social recognition. In all these cases, manipulations targeting the oxytocinergic system took place before the social interaction. In our study, OTA was infused after the encounter, and its effect was evaluated 1 week later. This result, along with the lower Otr mRNA levels found in the MeA of the 'stressed and subordinated' group than in the 'unstressed and subordinated', status of which is not maintained in the long term, indicates a role for this system in the MeA toward the potentiation of memory for the subordinate status after a first social encounter. Exposure to stressors was shown to increase the release of OT in different brain areas (Wotjak et al, 1998; Engelmann et al, 1999; Neumann, 2007; Ebner et al, 2000, 2005), and cell culture experiments showed that OT can lead to a downregulation of OTR (Insel et al, 1992; Di ScalaGuenot and Strosser, 1995). Although we could not measure neuropeptide release in the MeA during the social encounter due to technical limitations, it is tempting to speculate that OT release in the MeA during the first encounter in the stressed animals differed from the other experimental groups. Moreover, OT release in the amygdala was shown to lead to a more passive coping style (Ebner et al, 2005). A passive coping style is associated with a lower aggression level (reviewed by Koolhaas et al, 2010). Thus, in our model, exposure to acute stress might lead to a more passive coping style through an increased OT release in the amygdala, and this, in turn, has a role in the stressed rat becoming subordinate.

Interestingly, the $\mathrm{MeA}$ is one of the first brain areas within the social information processing pathways to become activated after exposure to a conspecific mice (Bielsky and Young, 2004; Ferguson et al, 2001). Work in OT knockout mice has shown that OT in the MeA is essential for the processing or initial retention of social information. These mice can form a spatial memory and have normal smell, but cannot form social memories. Infusion of OT into the MeA is sufficient to restore the social memory (Ferguson et al, 2000, 2001). OT knockout 
mice show normal social approach, social interaction and perception and recognition of social cues, which suggests that OT is selectively required for higher-order processing of social memory formation (Crawley et al, 2007). Therefore, it is plausible to hypothesize that the stress-induced enhancement of a memory for the subordinate status is linked to increased OT release in the MeA at the time of the first encounter and to the subsequent lower OTR expression.

Although we did not find a regulation of the V1aR, we cannot exclude the implication of these receptors in the phenomenon under study at other time points than the ones selected here for the gene expression analyses. Strong evidence in the literature links the vasopressinergic system and the lateral septum with social recognition. In rats, systemic or central AVP injections, as well as administration of V1ar overexpressing viral vectors in the LS, were shown to enhance social recognition (Le Moal et al, 1987; Dantzer et al, 1988; Popik et al, 1991; Popik and Van Ree, 1992; Engelmann and Landgraf, 1994), while converse effects (ie, disruption of social recognition) were found when $\mathrm{VlaR}$ antagonists were given or when $\mathrm{VlaR}$ were downregulated in the LS (Dantzer et al, 1987, 1988; Bluthe et al, 1990; Landgraf et al, 2003; van Wimersma Greidanus and Maigret, 1996; Everts and Koolhaas, 1997, 1999). V1aR knockout mice show impaired social recognition, with the LS, not the MeA, being particularly important for this effect (Bielsky et al, 2004). Increased levels of AVP release and $\mathrm{VlaR}$ activation have been suggested to have a role in increasing the duration of social memories (Bielsky et al, 2005). Thus, it is tempting to speculate that this receptor system might be involved in the modulation of the longterm expression of the subordinate status by stress. Further studies are in progress to evaluate this hypothesis.

The question arises as to which mechanisms could be engaged by the oxytocinergic system in its effect on the long-term establishment of subordinate social status. Although evidence is still scarce directly linking its memory-related effects and mediating mechanisms, there is increasing evidence supporting a potential link between the oxytocinergic system and glutamatergic transmission. Specifically, this link has been established in the amygdala in the context of coping with stress (Ebner et al, 2005; Bosch et al, 2007). Given the importance of the glutamatergic system in learning and memory processing, further studies are warranted to explore the potential role of this neurotransmitter system in the context of the behavioral effects described in this study.

In summary, we have presented evidence indicating that, along with the potentiation of a subordinate phenotype, stress triggers the OT neuropeptide pathway in the MeA, a brain region critically implicated in social recognition. Altogether, our findings suggest a role for the OTR in the $\mathrm{MeA}$ in the initial stages of the long-term establishment of a subordinate status within a dominance hierarchy.

\section{ACKNOWLEDGEMENTS}

This work was supported by Grants from the $\mathrm{EU} 7^{\text {th }}$ (FP7-HEALTH-F2M-2007-201600; MemStick) FP, the Swiss National Science Foundation (310000-120791; Sinergia CRSIK0-122697 and CRSIK0-122691) and the Swiss Network for International Studies (SNIS) to CS. We thank Grégoire Parchet and Angélique Vaucher for technical assistance and Prof Ruth Lüthi-Carter, Manuel Bueno, and Sylvain Lengacher for their advice on the gene expression experiments.

\section{DISCLOSURE}

The authors declare no conflict of interest.

\section{REFERENCES}

Benelli A, Bertolini A, Poggioli R, Menozzi B, Basaglia R, Arletti R (1995). Polymodal dose-response curve for oxytocin in the social recognition test. Neuropeptides 28: 251-255.

Bielsky IF, Hu SB, Ren X, Terwilliger EF, Young LJ (2005). The Vla vasopressin receptor is necessary and sufficient for normal social recognition: a gene replacement study. Neuron 47: 503-513.

Bielsky IF, Hu SB, Szegda KL, Westphal H, Young LJ (2004). Profound impairment in social recognition and reduction in anxiety-like behavior in vasopressin V1a receptor knockout mice. Neuropsychopharmacology 29: 483-493.

Bielsky IF, Young LJ (2004). Oxytocin, vasopressin, and social recognition in mammals. Peptides 25: 1565-1574.

Blanchard RJ, Flannelly KJ, Blanchard DC (1988). Life-span studies of dominance and aggression in established colonies of laboratory rats. Physiol Behav 43: 1-7.

Bluthe RM, Schoenen J, Dantzer R (1990). Androgen-dependent vasopressinergic neurons are involved in social recognition in rats. Brain Res 519: 150-157.

Bosch O, Sartori SB, Singewald N, Neumann ID (2007). Extracellular amino acid levels in the paraventricular nucleus and the central amygdala in high- and low-anxiety dams rats during maternal aggression: regulation by oxytocin. Stress 10: 261-270.

Choleris E, Little SR, Mong JA, Puram SV, Langer R, Pfaff DW (2007). Microparticle-based delivery of oxytocin receptor antisense DNA in the medial amygdala blocks social recognition in female mice. Proc Natl Acad Sci USA 104: 4670-4675.

Cordero MI, Sandi C (2007). Stress amplifies memory for social hierarchy. Front Neurosci 1: 175-184.

Crawley JN, Chen T, Puri A, Washburn R, Sullivan TL, Hill JM et al. (2007). Social approach behaviors in oxytocin knockout mice: comparison of two independent lines tested in different laboratory environments. Neuropeptides 41: 145-163.

Dantzer R, Bluthe RM, Koob GF, Le Moal M (1987). Modulation of social memory in male rats by neurohypophyseal peptides. Psychopharmacology 91: 363-368.

Dantzer R, Koob GF, Bluthe RM, Le Moal M (1988). Septal vasopressin modulates social memory in male rats. Brain Res 457: 143-147.

Delville Y, Mansour KM, Ferris CF (1996). Serotonin blocks vasopressin-facilitated offensive aggression: interactions within the ventrolateral hypothalamus of golden hamsters. Physiol Behav 59: 813-816.

Di Scala-Guenot D, Strosser MT (1995). Downregulation of the oxytocin receptor on cultured astroglial cells. Am J Physiol 268: C413-C418.

Ebner K, Bosch OJ, Kromer SA, Singewald N, Neumann ID (2005). Release of oxytocin in the rat central amygdala modulates stresscoping behavior and the release of excitatory amino acids. Neuropsychopharmacology 30: 223-230.

Ebner K, Wotjak CT, Landgraf R, Engelmann M (2000). A single social defeat experience selectively stimulates the release of oxytocin, but not vasopressin, within the septal brain area of male rats. Brain Res 872: 87-92. 
Engelmann M, Ebner K, Landgraf R, Holsboer F, Wotjak CT (1999). Emotional stress triggers intrahypothalamic but not peripheral release of oxytocin in male rats. J Neuroendocrinol 11: 867-872.

Engelmann M, Ebner K, Wotjak CT, Landgraf R (1998). Endogenous oxytocin is involved in short-term olfactory memory in female rats. Behav Brain Res 90: 89-94.

Engelmann M, Landgraf R (1994). Microdialysis administration of vasopressin into the septum improves social recognition in Brattleboro rats. Physiol Behav 55: 145-149.

Engelmann M, Wotjak CT, Ebner K, Landgraf R (2000). Behavioural impact of intraseptally released vasopressin and oxytocin in rats. Exp Physiol 85: 125S-130S.

Engelmann M, Wotjak CT, Neumann ID, Ludwig M, Landgraf R (1996). Behavioral consequences of intracerebral vasopressin and oxytocin: focus on learning and memory. Neurosci Biobehav Rev 20: 341-358.

Everts HG, Koolhaas JM (1997). Lateral septal vasopressin in rats: role in social and object recognition? Brain Res 760: 1-7.

Everts HG, Koolhaas JM (1999). Differential modulation of lateral septal vasopressin receptor blockade in spatial learning, social recognition, and anxiety-related behaviors in rats. Behav Brain Res 99: 7-16.

Ferguson JN, Aldag JM, Insel TR, Young LJ (2001). Oxytocin in the medial amygdala is essential for social recognition in the mouse. J Neurosci 21: 8278-8285.

Ferguson JN, Young LJ, Hearn EF, Matzuk MM, Insel TR, Winslow JT (2000). Social amnesia in mice lacking the oxytocin gene. Nat Genet 25: 284-288.

Ferguson JN, Young LJ, Insel TR (2002). The neuroendocrine basis of social recognition. Front Neuroendocrinol 23: 200-224.

Ferris CF, Albers HE, Wesolowski SM, Goldman BD, Luman SE (1984). Vasopressin injected into the hypothalamus triggers a stereotypic behavior in golden hamsters. Science 224: 521-523.

Gimpl G, Fahrenholz F (2001). The oxytocin receptor system: structure, function, and regulation. Physiol Rev 81: 629-683.

Goodson JL (2005). The vertebrate social behavior network: evolutionary themes and variations. Horm Behav 48: 11-22.

Herrero AI, Sandi C, Venero C (2006). Individual differences in anxiety traits are related to spatial learning abilities and hippocampal expression of mineralocorticoid receptors. Neurobiol Learn Mem 86: 150-159.

Insel TR, Winslow JT, Witt DM (1992). Homologous regulation of brain oxytocin receptors. Endocrinology 130: 2602-2608.

Irvin RW, Szot P, Dorsa DM, Potegal M, Ferris CF (1990). Vasopressin in the septal area of the golden hamster controls scent marking and grooming. Physiol Behav 48: 693-699.

Koolhaas JM, de Boer SF, Coppens CM, Buwalda B (2010). Neuroendocrinology of coping styles: towards understanding the biology of individual variation. Front Neuroendocrinol 31: 307-321.

Landgraf R, Frank E, Aldag JM, Neumann ID, Sharer CA, Ren X et al. (2003). Viral vector-mediated gene transfer of the vole V1a vasopressin receptor in the rat septum: improved social discrimination and active social behaviour. Eur J Neurosci 18: 403-411.

Landgraf R, Wotjak CT, Neumann ID, Engelmann M (1998). Release of vasopressin within the brain contributes to neuroendocrine and behavioral regulation. Prog Brain Res 119: 201-220.

Le Moal M, Dantzer R, Michaud B, Koob GF (1987). Centrally injected arginine vasopressin (AVP) facilitates social memory in rats. Neurosci Lett 77: 353-359.

Neumann ID (2007). Stimuli and consequences of dendritic release of oxytocin within the brain. Biochem Soc Trans 35: 1252-1257.
Neumann ID, Krömer SA, Toschi N, Ebner K (2000). Brain oxytocin inhibits the (re)activity of the hypothalamo-pituitaryadrenal axis in male rats: involvement of hypothalamic and limbic brain regions. Regul Pept 96: 31-38.

Newman SW (1999). The medial extended amygdala in male reproductive behavior. A node in the mammalian social behavior network. Ann NY Acad Sci 877: 242-257.

Ostrowski NL (1998). Oxytocin receptor mRNA expression in rat brain: implications for behavioral integration and reproductive success. Psychoneuroendocrinology 23: 989-1004.

Ostrowski NL, Lolait SJ, Young III WS (1994). Cellular localization of vasopressin V1a receptor messenger ribonucleic acid in adult male rat brain, pineal, and brain vasculature. Endocrinology 135: 1511-1528.

Patchev VK, Schlosser SF, Hassan AH, Almeida OF (1993). Oxytocin binding sites in rat limbic and hypothalamic structures: site-specific modulation by adrenal and gonadal steroids. Neuroscience 57: 537-543.

Popik P, Van Ree JM (1991). Oxytocin but not vasopressin facilitates social recognition following injection into the medial preoptic area of the rat brain. Eur Neuropsychopharmacol 1: 555-560.

Popik P, Van Ree JM (1992). Long-term facilitation of social recognition in rats by vasopressin related peptides: a structureactivity study. Life Sci 50: 567-572.

Popik P, Vetulani J (1991). Opposite action of oxytocin and its peptide antagonists on social memory in rats. Neuropeptides 18: 23-27.

Popik P, Vetulani J, van Ree JM (1992). Low doses of oxytocin facilitate social recognition in rats. Psychopharmacology 106: 71-74.

Popik P, Vetulani J, Van Ree JM (1996). Facilitation and attenuation of social recognition in rats by different oxytocinrelated peptides. Eur J Pharmacol 308: 113-116.

Popik P, Wolterink G, De Brabander H, van Ree JM (1991). Neuropeptides related to [Arg8]vasopressin facilitates social recognition in rats. Physiol Behav 49: 1031-1035.

Timmer M, Sandi C (2010). A role for glucocorticoids in the longterm establishment of a social hierarchy. Psychoneuroendocrinology 35: 1543-1552.

Van Kreveld D (1970). A selective review of dominance-subordinate relations in animals. Genet Psychol Monogr 81: 143-173.

van Wimersma Greidanus TB, Maigret C (1996). The role of limbic vasopressin and oxytocin in social recognition. Brain Res 713: 153-159.

Veenema AH, Neumann ID (2008). Central vasopressin and oxytocin release: regulation of complex social behaviours. Prog Brain Res 170: 261-276.

Watters JJ, Wilkinson CW, Dorsa DM (1996). Glucocorticoid regulation of vasopressin V1a receptors in rat forebrain. Brain Res Mol Brain Res 38: 276-284.

Winslow JT, Insel TR (1993). Effects of central vasopressin administration to infant rats. Eur J Pharmacol 233: 101-107.

Wotjak CT, Ganster J, Kohl G, Holsboer F, Landgraf R, Engelmann M (1998). Dissociated central and peripheral release of vasopressin, but not oxytocin, in response to repeated swim stress: new insights into the secretory capacities of peptidergic neurons. Neuroscience 85: 1209-1222.

Wotjak CT, Kubota M, Liebsch G, Montkowski A, Holsboer F, Neumann ID et al. (1996). Release of vasopressin within the rat paraventricular nucleus in response to emotional stress: a novel mechanism of regulating adrenocorticotropic hormone secretion? J Neurosci 16: 7725-7732.

Supplementary Information accompanies the paper on the Neuropsychopharmacology website (http://www.nature.com/npp) 